\title{
Balanço Hídrico para Pinheiral, Rio de Janeiro
}

Antonio Passos Portilho1,4 (antonio.portilho@ifrj.edu.br); Marcelo Carazo Castro1 (marcelo.castro@ifrj.edu.br); Guilherme de Souza Alves2,5 (gs.alves1991@bol.com.br); Nathan Fernandes de Aguiar2,5

(nfaguiar@hotmail.com); Marilena Souza da Silva3,5(marys.s@hotmail.com)

1Docente; Instituto Federal de Educação, Ciência e Tecnologia do Rio de Janeiro - Campus Nilo Peçanha, Pinheiral-RJ. 2Discente do Curso Técnico em Agropecuária; Instituto Federal de Educação, Ciência e Tecnologia do Rio de Janeiro - Campus Nilo Peçanha, Pinheiral-RJ. 3Discente do Curso Técnico em Informática; Instituto Federal de Educação, Ciência e Tecnologia do Rio de Janeiro - Campus Nilo Peçanha, Pinheiral-RJ. 4autor para correspondência - endereço: Rua José Breves 550, centro, Pinheiral-RJ, 27197-000. 5Bolsista do Projeto Jovens

Talentos-Fundação de Apoio à Pesquisa do Estado do Rio de Janeiro(FAPERJ)/Centro de Ciência do Rio de Janeiro(CECIERJ).

\section{RESUMO}

O trabalho visou à obtenção do balanço hídrico climatológico pelo método de Thornthwaite \& Mather (1955) para o município de Pinheiral, localizado na região do Médio Paraíba Fluminense e sua aplicação no planejamento agropecuário local. Foram utilizados dados de 64 meses coletados a partir de abril de 2005 pela estação meteorológica automática do IFRJ em Pinheiral.

Palavras-chave: Balanço hídrico; planejamento agropecuário; irrigação.

\section{Water Balance for Pinheiral, RJ}

\section{ABSTRACT}

The work was aimed at achieving the climatic water balance by the method of Thornthwaite \& Mather(1955) for the city of Pinheiral, located in the Middle Paraiba Fluminense, and apply it to the local agricultural planning. We utilized data collected 64 months from April 2005 by the automatic weather station of the IFRJ in Pinheiral.

Keywords: Water balance; agricultural planning; irrigation.

\section{INTRODUÇÃO}

O solo agrícola pode ser visto como um reservatório de água onde as entradas e saídas podem ser contabilizadas por um balanço hídrico que respeita o Princípio de Conservação de Massa em um volume de solo vegetado. A entrada de água no solo refere-se à precipitação pluvial, à irrigação e à ascensão capilar enquanto a saída refere-se à evapotranspiração e à percolação. Genericamente, estas variáveis podem ser correlacionadas em o balanço hídrico como apresentado na equação 1.

$(P R C+I R R+A S C)-(E T+P E R)=A R M$

em que: $P R C=$ precipitação pluvial, $\mathrm{mm}$;

$$
\begin{aligned}
& \text { IRR = irrigação, mm; } \\
& \text { ASC = ascensão capilar, mm; } \\
& \text { ET = evapotranspiração, mm; } \\
& \text { PER = percolação, mm; } \\
& \text { ARM = variação do armazenamento de água no solo, mm. }
\end{aligned}
$$


O balanço hídrico, em função da aplicação a que se destina, pode ser elaborado em diversas bases temporais, como a diária e a mensal. Nesse sentido, Mota (1977) menciona que a base diária é preferida para as operações agrícolas do dia-a-dia, enquanto a mensal pode ser utilizada para o planejamento de longo prazo de recursos hídricos.

Para bases temporais de pequeno intervalo, Carvalho et al. (2009), por exemplo, utilizaram o balanço hídrico diário para indicar, de maneira precisa, o momento de irrigar e o volume de água a ser aplicado. Aliás, Moura et al. (1994) mencionam que o balanço hídrico é uma metodologia bastante empregada por diversos pesquisadores na determinação do consumo de água pelas culturas agrícolas, pois descreve as condições hídricas nas quais as mesmas se desenvolvem. Esses autores empregaram o método do balanço hídrico para estimar o consumo de água pela cultura da cenoura para a região de Piracicaba/SP. Já Silva et al. (2001) estimaram, com bons resultados, o consumo de água da mangueira irrigada utilizando para isso o método do balanço hídrico do solo apresentado na equação 1.

Nied et al. (2005) usaram o balanço hídrico diário para escolher a época de plantio do milho em Santa Maria-RS, que apresente o menor risco de ocorrência de deficiência hídrica, dentre as 42 datas simuladas.

Feiz \& Rangel (2008) estudaram a melhor época de semeadura da soja na região de Dourados-MS em função da deficiência hídrica e do fotoperíodo. Para análise da deficiência hídrica, os autores usaram o balanço hídrico diário e concluíram que a semeadura da soja, em novembro e dezembro, são mais favoráveis à região analisada.

Felicio et al. (1999) avaliaram a disponibilidade hídrica do solo em Capão Bonito-SP, entre 1991 e 1995, por meio de balanços hídricos decendiais, aplicando-os ao desempenho agronômico da triticale. Das três épocas de semeadura estudadas, os autores puderam recomendar uma que produziria melhores rendimentos, bem como genótipos mais adequados ao plantio em cada época de semeadura avaliada e ainda apresentaram um comparativo de desempenho de genótipos diferentes de triticale em uma mesma época de semeadura.

Para valores mensais, considerando a entrada apenas a partir da precipitação pluvial, Thornthwaite \& Mather (1955) propuseram uma metodologia de cálculo que efetuasse a formulação da equação 1 de forma genérica e facilitada para uma região qualquer. Vianello \& Alves (2006) mencionam que tal metodologia é amplamente adotada no mundo.

O balanço de água no solo, estimado pelo estudo de Thornthwaite \& Mather (1955) em escala mensal pode ser aplicado, de acordo com Dourado Neto et al. (2010), para caracterização hidrológica destinada ao manejo da água, para estudos ambientais e para o planejamento agrícola que define o uso da terra e as práticas agrícolas.

O balanço hídrico pode se referir a uma série longa de dados meteorológicos em termos de média mensal, recebendo neste caso o nome de balanço hídrico climatológico. Galvani (2008) menciona que tal balanço pode ser aplicado para: a) comparação da disponibilidade hídrica entre regiões diferentes; b) caracterização de períodos secos e seus efeitos na agricultura, como redução da produção e impactos sociais; c) zoneamento agroclimático classificando as regiões como sendo "apta", "marginal" ou "inapta" em função das exigências térmicas e hídricas de uma determinada cultura; d) determinação das melhores épocas de semeadura em função das restrições hídricas locais; e) comparação entre os anos padrões denominados "normais" com aqueles denominados "secos" e/ou "úmidos" e f) avaliação quantitativa das deficiências e excedentes hídricos permitindo uma comparação da intensidade da estação seca.

Além disso, Galvani (2008) usou o balanço hídrico climatológico de Thornthwaite \& Mather (1955) para comparar o clima das cidades de Piracicaba-SP, São Paulo-SP e Paris, França identificando regimes hídricos distintos de deficiência e excessos hídricos nestas localidades.

O uso de modelos estatísticos para previsão de safras é um fator chave para o agronegócio, pois permite conhecer antecipadamente a tendência de aumento ou redução da produção de uma cultura qualquer em função das características meteorológicas reinantes. No caso da cultura do citrus, Paulino et al. (2007) desenvolveram um modelo que emprega o balanço hídrico de Thornthwaite \& Mather (1955) para estimativa de produtividade de laranjeiras com base na influência de variáveis meteorológicas durante as fases de crescimento vegetativo, pré-florescimento, florescimento e início de crescimento dos frutos, para a região de Limeira/SP.

Já Dourado Neto et al. (1999) desenvolveram um modelo matemático cossenoidal que estima o armazenamento de água no solo com o objetivo de prever a produção de culturas agrícolas anuais, baseado igualmente no balanço hídrico de Thornthwaite \& Mather (1955).

Souza et al. (2006) estimaram a produtividade do eucalipto na Bacia do Rio Doce, em Minas Gerais, a partir do crescimento do mesmo e das chuvas ocorridas, empregando-se para tal o balanço hídrico com a mesma metodologia proposta por Thornthwaite \& Mather (1955).

Ribeiro et al. (2006) avaliaram as condições ambientais propícias para a ocorrência da indução do florescimento de laranjeiras no Estado de São Paulo e concluíram que a deficiência hídrica é a principal variá- 
vel ambiental de indução na região centro-norte do Estado de São Paulo. Nesse estudo, os autores usaram o balanço hídrico climatológico apresentado por Thornthwaite \& Mather (1955).

De acordo com Tubelis (1988), o balanço hídrico pode ser aplicado ao planejamento agrícola por meio da adequação do cultivo às condições climáticas locais evitando-se, assim, imprevistos e maiores prejuízos decorrentes das variáveis climáticas. Santos et al. (2010), por exemplo, elaboraram o balanço hídrico mensal para a região de Marinópolis-SP pelo método de Thornthwaite \& Mather (1955) com dados disponibilizados por uma estação agrometeorológica automática. Por meio dese estudo, os autores concluíram que haveria risco elevado com o cultivo, sem o uso de sistemas de irrigação, em oito meses do ano, naquela região.

Pruski et al. (2001) desenvolveram um modelo hidrológico para estimar o escoamento superficial em áreas sob condições agrícolas baseado em diversos processos associados ao balanço hídrico. O modelo pode ser utilizado, ainda, de acordo com seus autores, para o dimensionamento de estruturas hidráulicas, para o monitoramento ambiental e, também, para o manejo de sistemas de irrigação.

$\mathrm{Na}$ busca do conhecimento das características climáticas de um local qualquer e sua posterior comparação com outros lugares, são empregados Sistemas de Classificação Climáticas, dentre os quais se destacam o de Köppen e o de Thornthwaite. O sistema de Köppen é bastante empregado no mundo e considera apenas o tipo de vegetação natural como um indicador do clima, sendo recomendado apenas para estudos geográficos e climatológicos. O sistema de Thornthwaite difere do de Köppen devido à utilização de parâmetros do solo e de elementos meteorológicos, como a precipitação e temperatura sendo, por isso, mais adequado para aplicações agrícolas. Esse sistema possibilita, por exemplo, a extrapolação de informações agrícolas de uma zona para outra com mesmas características (Rolim et al., 2007).

Efetuando a classificação climática para o Estado de São Paulo, Rolim et al. (2007) observaram que o sistema de Thornthwaite apresentou melhores resultados em relação ao de Köppen, atribuindo isso a maior sensibilidade do mesmo às características de chuva, temperatura e relevo. Os autores concluíram que não se pode estabelecer uma relação entre estes dois sistemas de classificação climática.

Correia Filho et al. (2010) efetuaram o balanço hídrico climatológico para o Estado do Rio Grande do Norte utilizando para isso a metodologia de Thornthwaite \& Mather (1955) e identificaram regiões com semeIhança em excesso e em déficit hídrico naquele Estado.

Rolim et al. (2007) observaram uma boa relação entre a qualidade natural de bebida de café e os tipos de clima determinados pela classificação climática de Thornthwaite para o Estado de São Paulo. Eles observaram que os climas B3 e B4 correspondem à bebida tipo "Mole" e que os climas B2, C2 e B1 conferem à bebida, respectivamente, a denominação de "Dura adstringente", "Dura, pouco adstringente" e "Riada".

Um exemplo de zoneamento agrícola é o apresentado por Pommer et al. (2009) que analisaram o clima em Campos dos Goytacazes-RJ. Esses autores concluíram que esse município é adequado para a produção vitícola sendo possível a colheita em mais de uma época durante o ano.

Dantas et al. (2007) utilizaram o balanço hídrico pelo método de Thornthwaite \& Mather (1955) para avaliar as mudanças recentes no clima de Lavras-MG, em relação àquele observado no período de 1961 a 1990. Perceberam que a classificação climática de Thornthwaite mudou de B3r B'3a para B2r B'3a no período mais recente, porém não houve alteração na classificação climática de Köppen, permanecendo, então, Cwa.

O Instituto Nacional de Meteorologia mantém uma página na internet na qual é possível visualizar o balanço hídrico climatológico de suas estações em todo o território brasileiro (INMET, 2010). Entretanto, essas informações são apresentadas sob a forma gráfica, o que dificulta a obtenção de valores precisos e se restringem a locais bastante específicos. No Estado do Rio de Janeiro, por exemplo, são apenas nove estações.

O município de Pinheiral está localizado na região do Médio Paraíba Fluminense, na sub-bacia do ribeirão Cachimbal que compõe a bacia hidrográfica do rio Paraíba do Sul, localizada entre as latitudes $22^{\circ} 29^{\prime} 03^{\prime \prime} \mathrm{S}$ e $22^{\circ} 35^{\prime} 27^{\prime \prime} \mathrm{S}$ e entre as longitudes $43^{\circ} 54^{\prime} 49^{\prime \prime} \mathrm{W}$ e $44^{\circ} 04^{\prime} 05^{\prime \prime} \mathrm{W}$, numa altitude que varia entre 400 e 600 m. O clima da região, de acordo com a classificação de Köppen apresentado por Menezes (2008), apresenta duas formas distintas, a saber: Cwa representando clima temperado de inverno seco e verão chuvoso e Am que representa clima tropical chuvoso com inverno seco.

Apesar das informações genéricas a respeito da região de Pinheiral-RJ, ressalta-se que esse município não possui uma caracterização climática mais específica que possibilite um planejamento agropecuário mais apurado, como aquele obtido a partir do balanço hídrico. Assim, este trabalho visa à obtenção e análise do balanço hídrico no município de Pinheiral identificando, assim, elementos para o planejamento agropecuário local.

\section{MATERIAL E MÉTODOS}

Os dados meteorológicos utilizados neste trabalho foram obtidos na estação meteorológica automática marca Metos, modelo C-907C, instalada no Instituto 
Federal de Educação, Ciência e Tecnologia do Rio de Janeiro campus Nilo Peçanha, em Pinheiral-RJ, na latitude de $22^{\circ} 31^{\prime}$ S, longitude de $43^{\circ} 59^{\prime} \mathrm{W}$ e altitude de 396 $\mathrm{m}$. A base de dados empregada abrangeu o período de abril de 2005 a julho de 2010.

O balanço hídrico foi elaborado pelo método de Thornthwaite 7 Mather (1955), com a determinação da evapotranspiração, segundo, Thornthwaite (1948), conforme metodologias apresentadas por Vianello \& Alves (2006) e Pereira et al. (1997). Nesse balanço, considerou-se uma Capacidade de Água Disponível do perfil do solo de $100 \mathrm{~mm}$, por ser um valor normalmente empregado para classificação climática, de acordo com Vianello \& Alves (2006). Ressalta-se o atendimento da demanda hídrica de diversas culturas, segundo Correia Filho et al. (2010).

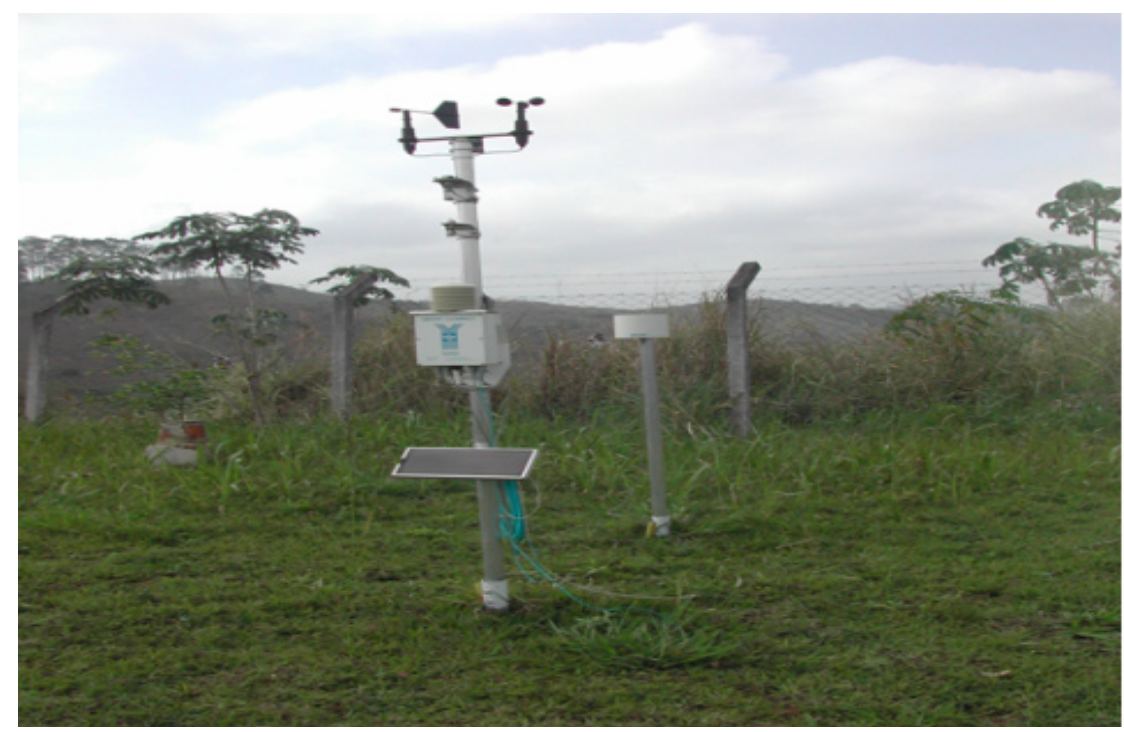

Figura 1: Visão da estação meteorológica do Campus Nilo Peçanha/Pinheiral do Instituto Federal de Educação, Ciência e Tecnologia do Rio de Janeiro.

\section{RESULTADOS E DISCUSSÃO}

O Quadro 1 apresentado a seguir, mostra o balanço hídrico para Pinheiral-RJ pelo método de Thorntwaite \& Mather (1955) e a Figura 2 mostra sua representação gráfica. Para o cálculo da evapotranspiração potencial não ajustada pelo método de Thornthwaite, segundo Vianello \& Alves (2006), encontrou-se o índice térmico anual (I) igual a 105,1322 e a constante "a" igual a 2,3085.

Quadro 1 - Balanço Hídrico pelo Método de Thornthwaite \& Mather (1955) para o Município de PinheiralRJ entre Abril de 2005 e Julho de 2010

\begin{tabular}{|c|c|c|c|c|c|c|c|c|c|c|}
\hline MÊS & $\mathbf{T}\left({ }^{\circ} \mathbf{C}\right)$ & $\begin{array}{c}\text { EP } \\
(\mathbf{m m})\end{array}$ & $\begin{array}{c}\mathbf{P} \\
(\mathbf{m m})\end{array}$ & $\begin{array}{c}\text { P-EP } \\
(\mathbf{m m})\end{array}$ & $\begin{array}{c}\text { Neg. Acum. } \\
(\mathbf{m m})\end{array}$ & $\begin{array}{c}\text { ARM } \\
(\mathbf{m m})\end{array}$ & $\begin{array}{c}\text { ALT } \\
(\mathbf{m m})\end{array}$ & $\begin{array}{c}\text { ER } \\
(\mathbf{m m})\end{array}$ & $\begin{array}{c}\text { DEF } \\
(\mathbf{m m})\end{array}$ & $\begin{array}{c}\text { EXC } \\
(\mathbf{m m})\end{array}$ \\
\hline JAN & 23,4 & 117 & 162 & 110 & - & 100 & - & 117 & - & 110 \\
\hline FEV & 24,0 & 108 & 162 & 54 & - & 100 & - & 108 & - & 54 \\
\hline MAR & 23,6 & 109 & 107 & -2 & -2 & 98 & -2 & 109 & - & - \\
\hline ABR & 21,6 & 82 & 60 & -22 & -24 & 79 & -19 & 79 & 3 & - \\
\hline MAI & 18,6 & 57 & 51 & -6 & -30 & 74 & -5 & 56 & 1 & - \\
\hline JUN & 17,5 & 46 & 24 & -22 & -52 & 59 & -15 & 39 & 7 & - \\
\hline JUL & 17,5 & 49 & 43 & -6 & -58 & 56 & -3 & 46 & 3 & - \\
\hline AGO & 18,9 & 61 & 34 & -27 & -85 & 43 & -13 & 47 & 14 & - \\
\hline SET & 19,1 & 63 & 52 & -11 & -96 & 38 & -5 & 57 & 6 & - \\
\hline OUT & 21,8 & 94 & 126 & 32 & -36 & 70 & 32 & 94 & - & - \\
\hline NOV & 22,1 & 98 & 211 & 113 & - & 100 & 30 & 98 & - & 83 \\
\hline DEZ & 22,7 & 111 & 119 & 8 & - & 100 & - & 111 & - & 8 \\
\hline $\boldsymbol{\Sigma}$ & - & 995 & 1216 & 221 & - & - & 0 & 961 & 34 & 255 \\
\hline
\end{tabular}


Onde $\mathrm{T}$ = temperatura média mensal; $\mathrm{EP}=$ evapotranspiração potencial; $\mathrm{P}=$ precipitação; Neg. Acum. = negativo acumulado; $\mathrm{ARM}=$ armazenamento de água no solo; $\mathrm{ALT}$ = alteração do armazenamento; ER = evapotranspiração real; DEF = deficiência hídrica; EXC = excedente hídrico.

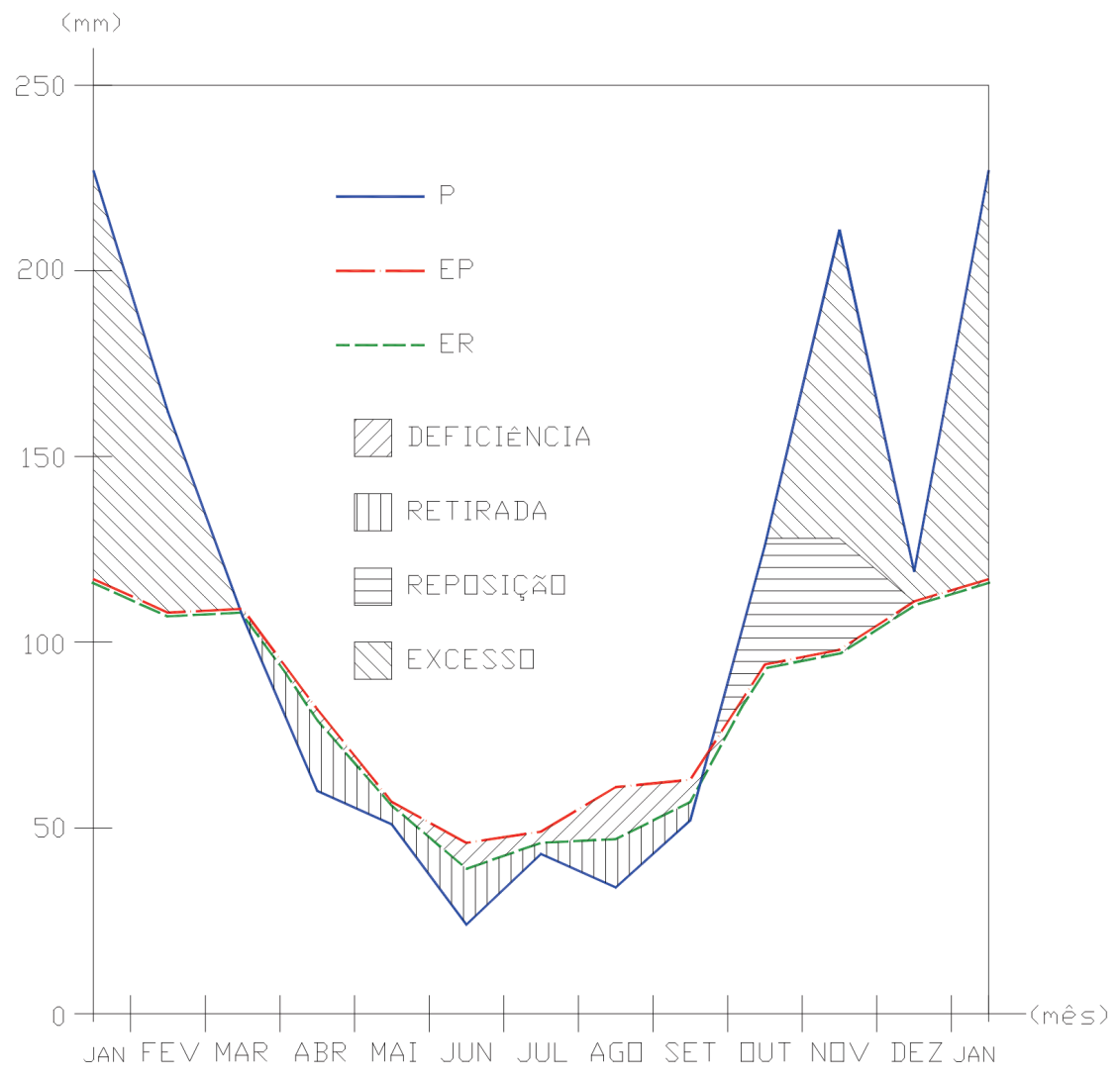

Figura 2 - Representação do Balanço Hídrico para o Município de Pinheiral-RJ apresentado no Quadro 1, onde P $=$ precipitação, $\mathrm{EP}=$ evapotranspiração potencial, ER = evapotranspiração real

Camargo \& Camargo (1993) mencionam que o balanço hídrico tradicional de Thornthwaite \& Mather (1955), como apresentado na Figura 2, é representado por linhas que indicam a precipitação mensal $(P)$ e a evapotranspiração potencial (EP). Essa última corresponde, de acordo com esses autores, à precipitação ideal no período de forma a não sobrar nem faltar água no solo para uso das plantas.

Em sua forma gráfica tradicional de apresentação do balanço hídrico (Figura 2), tem-se informações completas do mesmo, como deficiências e excedentes hídricos, retirada e reposição de água no solo. Essas informações, segundo Camargo \& Camargo (1993), às vezes dificulta a interpretação dos mesmos e, por isso, os autores desenvolveram uma representação gráfica simplificada dos resultados do balanço hídrico de Thornthwaite \& Mather (1955) empregando apenas informações de deficiência e excedentes hídricos.

Nessa mesma linha de simplificação das informações do balanço hídrico, como apresentado no Quadro 1, Pereira (2005) desenvolveu uma metodologia que suprimiu a coluna de "Negativo Acumulado" do balanço hídrico de Thornthwaite \& Mather (1955), sem que se alterasse os valores finais de evapotranspiração real, deficiência e excesso hídrico numa simplificação que visa a facilitação dos cálculos tornando, assim, o entendimento do balanço hídrico mais fácil.

Pelo Quadro 1, a precipitação média mensal observada foi de $101,3 \mathrm{~mm}$ e a precipitação média total anual foi de $1216 \mathrm{~mm}$, sendo os meses de janeiro e novembro os mais chuvosos com $227 \mathrm{~mm}$ e $211 \mathrm{~mm}$, respectivamente registrados. Os meses de junho e agosto foram os mais secos, com valores médios registrados de $24 \mathrm{~mm}$ e $37 \mathrm{~mm}$, respectivamente. As maiores demandas evapotranspirométricas médias mensais foram observadas em janeiro e dezembro e as menores em junho e junho, respectivamente $117 \mathrm{~mm}, 111 \mathrm{~mm}, 46 \mathrm{~mm}$ e $49 \mathrm{~mm}$, com um valor total médio anual de $995 \mathrm{~mm}$ e valor médio mensal de $82,9 \mathrm{~mm}$.

A evapotranspiração potencial no verão foi de $336 \mathrm{~mm}$. Observou-se, ainda, a existência de uma deficiência hídrica anual de $34 \mathrm{~mm}$, que se estende por um 
período de seis meses, de abril a setembro, com maior intensidade em agosto, no valor de $14 \mathrm{~mm}$. Já o excesso hídrico anual foi de $255 \mathrm{~mm}$, observado entre os meses de novembro e fevereiro, com pico em janeiro de 110 $\mathrm{mm}$. Outros valores de evapotranspiração, precipitação, excessos e deficiências hídricas podem ser vistos no Quadro 1 e na Figura 2.

A estação do Instituto Nacional de Meteorologia mais próxima de Pinheiral é a de Piraí-RJ, como apresentado por INMET (2010), distante aproximadamente $16 \mathrm{~km}$ da estação empregada neste trabalho. Observase pelo balanço hídrico climatológico desta estação, referente ao período de 1961 a 1990, que o excedente hídrico ocorre ao longo de seis meses entre novembro e abril, com valores máximos em dezembro e janeiro, contra apenas os quatro meses observados em Pinheiral. Já o déficit de água no solo ocorre ao longo de quatro meses, entre junho e setembro, com valores mais pronunciados em agosto, contra os seis meses observados em Pinheiral. Na estação do INMET em Piraí, geralmente, observa-se, em termos anuais, um excedente muitas vezes superior ao déficit, o que foi também observado em Pinheiral. Apesar de os balanços hídricos de Pinheiral e Piraí terem um mesmo comportamento geral com relação aos períodos de ocorrência dos excessos e deficiências hídricas ao longo do ano, o clima de Pinheiral apresenta-se mais seco que o de Piraí.

Mota (1977) apresenta valores médios mensais de deficiência e excesso de água no solo obtidos pelo balanço hídrico climatológico realizado para o período de 1931 a 1960, bem como de precipitações mensais, referentes a 28 cidades pertencentes as cinco regiões geográficas brasileiras. Estas 28 cidades estão assim distribuídas: oito na região Norte, cinco na região Nordeste, sete na região Sudeste, três na região CentroOeste e cinco na região Sul. A precipitação anual média das 28 cidades é de $1742 \mathrm{~mm}$, com máximo de 2921 $\mathrm{mm}$ em Uaupés-AM e mínimo de $477 \mathrm{~mm}$ em Macau$\mathrm{RN}$. A deficiência de água no solo média é de $227 \mathrm{~mm}$ com maior valor em Macau-RN, menor valor não nulo de $25 \mathrm{~mm}$ em Porto Alegre-RS e 10 valores nulos, sendo quatro na região Sul, dois nas regiões Norte e Sudeste, e um nas regiões Centro-Oeste e Nordeste. Outro aspcto significativo é que o excesso hídrico médio é de $682 \mathrm{~mm}$, com maior valor de $1989 \mathrm{~mm}$ em Paracatu-MG, menor valor não nulo de 192 mm em Cuiabá-MT e quatro valores nulos, sendo três na região nordeste e um na região centro-oeste. Comparando estas cidades com $\mathrm{Pi}$ nheiral, tem-se que 17 delas possuem deficiência hídrica superior a de Pinheiral e 21 apresentaram um excesso hídrico superior a ela, embora 22 dessas cidades apresentem precipitação média anual superior à Pinheiral.

Esse contexto indica que, no Brasil tomando-se como base apenas os valores apresentados por Mota (1977), Pinheiral é uma cidade com baixo volume de chuvas, todavia com boa distribuição delas e capaz de equilibrar, satisfatoriamente, o gasto de água pelas culturas perenes ao longo do ano.

Comparando-se as características climáticas de Pinheiral, conforme apresentado pelo balanço hídrico no Quadro 1, com as de Paris, na França, apresentadas por Galvani (2008), observa-se que: a) a precipitação total anual em Pinheiral é $87 \%$ maior, respectivamente $1216 \mathrm{~mm}$ e $650 \mathrm{~mm}$ para Pinheiral e Paris; b) a evapotranspiração real total anual em Pinheiral é $69 \%$ maior, respectivamente $961 \mathrm{~mm}$ e $567 \mathrm{~mm}$; c) o excesso hídrico total anual em Pinheiral é $211 \%$ maior, respectivamente $255 \mathrm{~mm}$ e $82 \mathrm{~mm}$, sendo que em ambas cidades ele ocorre com maior intensidade nos meses de janeiro e fevereiro; d) a deficiência hídrica total anual em Pinheiral é $48 \%$ menor, respectivamente $34 \mathrm{~mm}$ e $66 \mathrm{~mm}$, ocorrendo em maior intensidade em ambas as localidades entre os meses de julho e setembro. Apesar da grande diferença absoluta de chuva entre as duas cidades, equivalente a $566 \mathrm{~mm}$, a diferença entre os excessos hídricos, bem como a diferença entre as deficiências hídricas, foram significativamente menor. Isso decorre do fato da diferença das evapotranspirações reais totais anuais ser significativamente maior em Pinheiral, em valores absolutos, equivalente no caso a $394 \mathrm{~mm}$, motivado principalmente pela grande diferença de temperatura média anual, que em Pinheiral é de $20,9^{\circ} \mathrm{C}$ e em Paris é de $12,0^{\circ} \mathrm{C}$.

Para fins de classificação climática de Pinheiral-RJ pelo sistema de Thornthwaite, de acordo com metodologia apresentada por Vianello \& Alves (2006), obteve-se Índice Hídrico, Índice de Aridez e Índice de Umidade, respectivamente de 25,6; 3,4 e 22,2. Esses valores possibilitam a classificação climática do município como B1r B'3 a', ou seja, clima úmido, com pequena deficiência hídrica (nos meses de abril a setembro), mesotérmico, com evapotranspiração potencial anual de $995 \mathrm{~mm}$ e concentração da evapotranspiração potencial no verão igual a $33,8 \%$.

A referida classificação pode ser correlacionada à qualidade esperada de bebida de café. Historicamente, Menezes (2008) menciona que a região de Pinheiral-RJ foi o principal centro de produção nacional desta cultura durante várias décadas do século XIX. Extrapolando as características das zonas agroecológicas analisadas por Rolim et al. (2007) no Estado de São Paulo para Pinheiral-RJ, com base na mesma classificação climática de Thornthwaite, no caso B1, pode-se esperar que o café produzido em Pinheiral-RJ proporcione uma bebida do tipo "Riada".

\section{CONCLUSÃO}

Uma vez que a precipitação anual registrada foi superior à evapotranspiração potencial anual, respecti- 
vamente $1.216 \mathrm{~mm}$ e $995 \mathrm{~mm}$, o volume de chuvas que ocorreram seriam suficientes para atender a toda demanda hídrica das culturas que utilizam uma CAD equivalente a $100 \mathrm{~mm}$, se elas ocorressem de forma mais uniforme ao longo do ano.

O município de Pinheiral-RJ apresenta seis meses de deficiência hídrica no solo e quatro de excesso hídrico, de forma que o plantio das culturas anuais deveria ser realizado até outubro e a colheita deveria ser feita, preferencialmente, de abril a setembro.

Em síntese, para o planejamento das atividades agrícolas em Pinheiral-RJ, espera-se que a agricultura de sequeiro tenha seu melhor desempenho nos meses de novembro, dezembro, janeiro e fevereiro, que são os mais úmidos; ao passo que nos meses de julho, agosto e setembro, o cultivo de culturas anuais necessita de irrigação suplementar devido aos menores níveis de armazenamento de água no solo.

\section{REFERÊNCIAS BIBLIOGRÁFICAS}

CAMARGO, Marcelo Bento Paes de; CAMARGO, Ângelo Paes de. Representação gráfica informatizada do extrato do balanço hídrico de Thornthwaite e Mather. Bragantia, Campinas, v. 52, n. 2, 1993.

CARVALHO, M. A. de et al. Sistema de suporte à decisão para alocação de água em projetos de irrigação.

Revista Brasileira de Engenharia Agrícola e Ambiental, Campina Grande, v. 13, n. 1, fev. 2009.

CORREIA FILHO, W. L. F. et al. Estimativa do Balanço Hídrico Climatológico para o Estado do Rio Grande do Norte. In: CONGRESSO BRASILEIRO DE METEOROLOGIA, 16., 2010, Belém. Anais... Rio de Janeiro: Sociedade Brasileira de Meteorologia, 2010.

DANTAS, A. A. A.; CARVALHO, L. G. de; FERREIRA, E. Classificação e tendências climáticas em Lavras, MG. Ciência e Agrotecnologia, Lavras, v. 31, n. 6, dez. 2007.

DOURADO-NETO, D. et al. Balance hídrico ciclico y secuencial: estimación de almacenamiento de agua en el suelo. Scientia Agricola, Piracicaba, v. 56, n. 3, jul. 1999.

DOURADO-NETO, D. et al. General procedure to initialize the cyclic soil water balance by the Thornthwaite and Mather method. Scientia Agricola, Piracicaba, v. 67, n. 1, fev. 2010.

FELICIO, J. C. et al. Épocas de semeadura de triticale em Capão Bonito, SP. Pesquisa Agropecuária Brasileira, Brasília, v. 34, n. 12, dez. 1999.
FIETZ, Carlos R.; RANGEL, Marco A. S. Época de semeadura da soja para a região de Dourados - MS, com base na deficiência hídrica e no fotoperíodo. Engenharia Agrícola, Jaboticabal, v. 28, n. 4, dez. 2008.

GALVANI, Emerson. Estudo comparativo dos elementos do Balanço Hídrico Climatológico para duas cidades do Estado de São Paulo e para Paris. Confins, n.4, 2008. Disponível em: <http://confins.revues.org/4733>. Acesso em: 26 dez. 2010.

INSTITUTO NACIONAL DE METEOROLOGIA (INMET). Balanço hídrico climático. Disponível em: <http://www. inmet.gov.br/html/agro.php?lnk=Hídrico\%20Climático>. Acesso em: 29 dez 2010.

MENEZES, Carlos Eduardo Gabriel. Integridade de paisagem em função de manejo e atributos de solos em sub-bacia no ambiente mar de morros, médio vale do Paraíba do Sul, Pinheiral-RJ. 2008. 234 f. Tese (Doutorado em Agronomia) - Instituto de Agronomia, Universidade Federal Rural do Rio de Janeiro, Seropédica.

MOTA, Fernando Silveira da. Meteorologia Agrícola. São Paulo: Nobel, 1977. 379p.

MOURA, M.V.T. et al. Estimativa do consumo de água na cultura da cenoura (Daucus carota, L.) v. nantes superior, para a região de Piracicaba, através do método do balanço hídrico. Scientia Agricola, Piracicaba, v. 51, n. 2, ago. 1994.

NIED, A. H. et al. Épocas de semeadura do milho com menor risco de ocorrência de deficiência hídrica no município de Santa Maria, RS, Brasil. Ciência Rural, Santa Maria, v. 35, n. 5, out. 2005.

PAULINO, S. E. P. et al. Agrometeorological models for "Valencia" and "Hamlin" sweet oranges to estimate the number of fruits per plant. Scientia Agricola, Piracicaba, v. 64, n. 1, fev. 2007.

PEREIRA, Antonio Roberto. Simplificando o balanço hídrico de Thornthwaite-Mather. Bragantia, Campinas, v. 64 , n. 2, 2005.

PEREIRA, A. R.; Nova, N. A. V.; Sediyama, G. C. Evapo(transpi)ração. Piracicaba, FEALQ, 1997. 183p.

POMMER, C. V. et al. Potencial climático para a produção de uvas em Campos dos Goytacazes, região norte Fluminense. Revista Brasileira de Fruticultura, Jabo-ticabal, v. 31, n. 4, dez. 2009. 
PRUSKI, F. F.; RODRIGUES, L. N.; SILVA, D. D. da. Modelo hidrológico para estimativa do escoamento superficial em áreas agrícolas. Revista Brasileira de Engenharia Agrícola e Ambiental, Campina Grande, v. 5, n. 2, maio 2001.

RIBEIRO, R. V.; MACHADO, E. C.; BRUNINI, O. Ocorrência de condições ambientais para a indução do florescimento de laranjeiras no Estado de São Paulo. Revista Brasileira de Fruticultura, Jaboticabal, v. 28, n. 2, ago. 2006.

ROLIM, G. de S. et al. Classificação climática de Köppen e de Thornthwaite e sua aplicabilidade na determinação de zonas agroclimáticas para o estado de São Paulo. Bragantia, Campinas, v. 66, n. 4, 2007.

SANTOS, G. O.; HERNANDEZ, F. B. T.; ROSSETTI, J. C. Balanço hídrico como ferramenta ao planejamento agropecuário para a região de Marinópolis, noroeste do Estado de São Paulo. Revista Brasileira de Agricultura Irrigada, Fortaleza, v.4, n. 3, p.142-149, 2010. Disponível em: $\quad<$ http://www.inovagri.com.br/index.php/ category/artigos/ >. Acesso em: 20 dez. 2010.

SILVA, V. de P. R. da et al. Estimativa da evapotranspiração da mangueira com base no balanço hídrico do solo. Revista Brasileira de Engenharia Agrícola e Ambiental, Campina Grande, v.5, n.3, dez. 2001.

SOUZA, M. J. H. de et al. Disponibilidade hídrica do solo e produtividade do eucalipto em três regiões da Bacia do Rio Doce. Revista Árvore, Viçosa, v.30, n.3, jun. 2006.

THORNTHWAITE, C.W. An approach towards a rational classification of climate. Geographical Review, London, v.38, p.55-94, 1948.

THORNTHWAITE, C.W.; MATHER, J.R. The water balance. Centerton, NJ: Drexel Institute of Technology, Laboratory of Climatology, 1955. 104p. (Publications in Climatology, v.8, n.1)

TUBELIS, Antônio. A chuva e a produção agrícola. São Paulo: Nobel, 1988. 86 p.

VIANELLO, Rubens Leite; ALVES, Adail Ranier. Meteorologia básica e aplicações. Viçosa: UFV. 